\title{
forestry in action
}

\section{New Look Fire Bombing}

Fire bombing has passed through many phases since the days of dropping water bags. A recent development is the membrane tank system pioneered by the Field Aviation Co. Ltd. and successfully tested around the world.

This system is practical for land based planes. This is particularly so where large lakes do not exist.

The DeHavilland Twin Otter Plane was selected as the ideal carrier for the new tank system. The arrangement includes a rectangular tank of two 12 foot $\times 28$ inch sections, capable of holding 600 U.S. gallons and mounted on the underside of the plane. An expandable fabric membrane supports the fluid and is jettisoned with the load. At the required moment of release, four knives are programmed to cut the entire perimeter and drop the fluid in an uninterrupted homogeneous mass. By means of a simple setting in the cockpit the pilot can select either a deep penetration through dense tree cover or lay a fire line up to six hundred feet in length. This also gives a strip of uniform wetness thirty feet wide.

Cockpit controls permit the pilot to predetermine air speed and altitude and programme the mode of drop on any given bombing run.

The system also permits ready change-over from fire bombing duties to the more normal passenger activities. This can be accomplished at any base of operations.

Contributed by the DeHavilland Aircraft of Canada, Ltd., Downsview, Ontario.

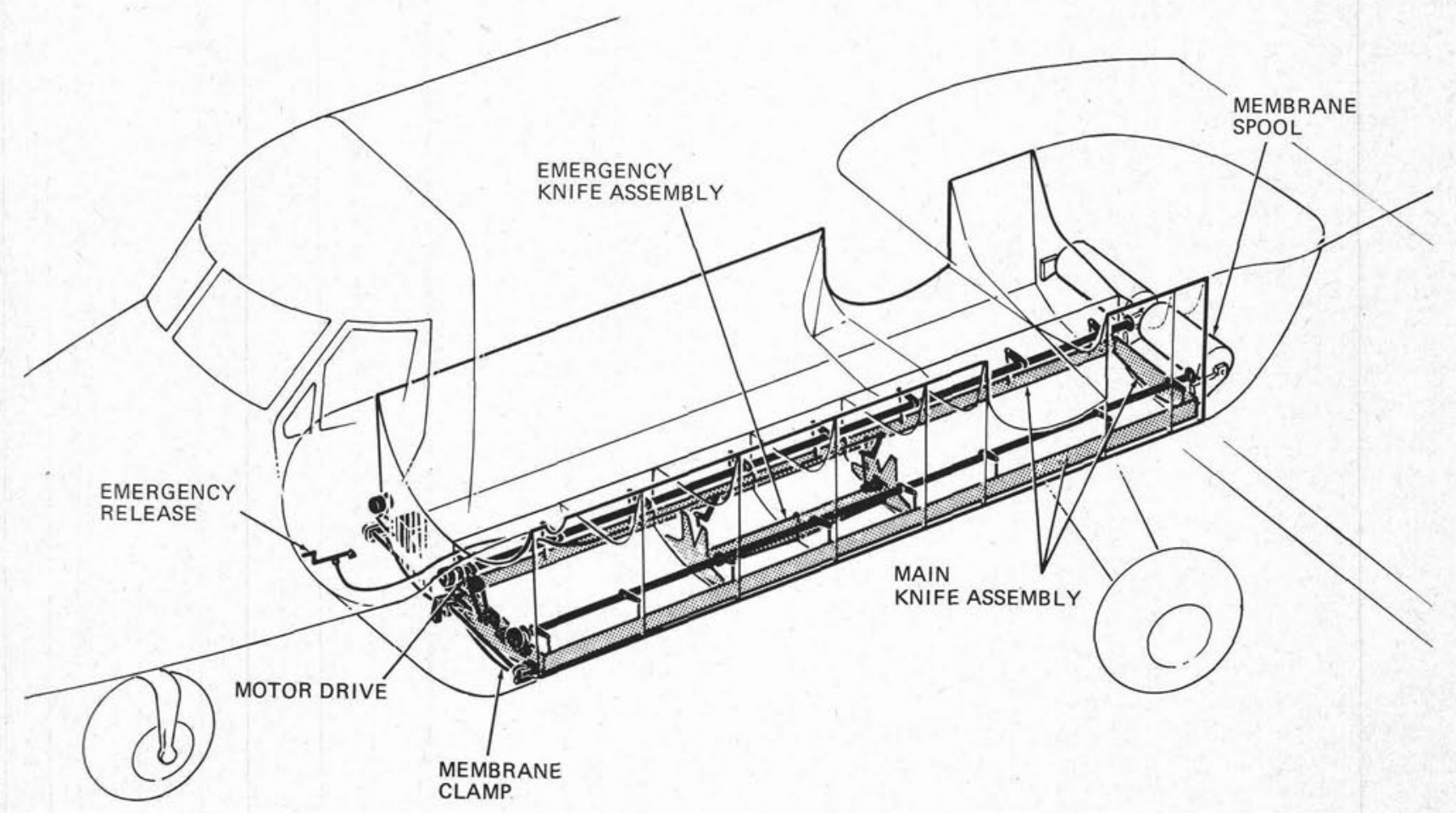




\section{One Million 'Mud-Packs'}

\section{Come Through}

\section{A Tough Year Well}

\section{An assessment of the 1st Year Survival of Pelton 'Mud-Packs'}

In the Spring of 1969 over one million Douglas fir 'mud-packs' were planted operationally by Pacific Logging Company Limited, at Sooke, and Lake Cowichan on Vancouver Island, B.C. (Figure 1). 844,600 of these were planted in the Lake Cowichan area and the 1st year survival results are reported here as the basis for discussion.

The Lake Cowichan area is a relatively tough one from a reforestation point of view with its climatic extremes and rocky granodiorite planting sites up to $2,600 \mathrm{ft}$. in elevation. 1969 was particularly severe both because of the late spring and because of hot dry weather experienced in May and June during the planting operation. Experience in this area indicates the weighted average survival for conventional bare-root mattock planting to be $61 \%$, varying from $30-79 \%$. The first year survival of 'mudpacks' in this poor year was $70 \%$, varying from $52-86 \%$.

Other features of this dibble planting technique were as follows:

1. Planting production per man day was doubled, from 650 bare-root to 1,200 with mud-packs. The crews were on an incentive bonus basis; this is an important factor where labour supply is critical. Production varied from 1,000 per man day on poor areas to 1,450 per man day on good areas.

2. Planting stock was lifted in November and December and mud-packed and cold stored for $4 \frac{1}{2-}$ 5 months prior to planting. This stock gave a survival rate of $75-85 \%$ (Figure 2 ).

3. At Sooke a further 166,600 'mud-packs' were planted. The weighted average survival was $81.6 \%$ varying from $78-88 \%$.

4. In the generally difficult planting sites being planted much more uniform stocking levels were achieved than with bare-root seedlings.

5. The total cost of planting 'mud-packs' was about the same as the cost for bare-root seedlings.

With a much better drying process now in use and with some encouraging tests with vermiculite in the 'pack', future results can only improve. Other tests now underway using dilute solutions of "Jiffy Gro" to stimulate root activity may also contribute greatly to initial survival and growth. The addition of suitable fertilizers to the 'pack' is an area in which research is needed.

It is the writer's considered opinion that the 'mudpack' is a good substitute for conventional bareroot mattock planting, especially in areas where the results of bare-root planting have been something less than satisfactory. This generalization assumes good planning, handling and quality control as would be expected for bare-root. Ideally the 'mud-pack' plant should be in the nursery so that lifted stock can be 'mudpacked' with a minimum of delay.

Other more specific predictions are: -

1. The 'mud-pack' will give consistently higher survival rates on an operational basis than bareroot.

2. The 'mud-pack' will give initial growth rates that are superior to those of 'bare-root'.

3. A sturdy 1-0 Douglas fir 'mud-pack' may become the optimum tree, and if so, will create cost savings in the nursery, the 'mud-pack' plant and in the final planting operation.

4. Increased survival and better initial stocking levels will reduce re-planting and 'fill-in' planting cost considerably.

5. Increased planting rates do considerably reduce supervision time required, and will also allow more trees to be planted at the best time of the year, thus enhancing the overall survival and growth results obtained.

If it were not for the fact that we do now have this 'mud-pack' as an alternative to the mattock planting technique of the '30's, it would be impossible to cope with an expanding Company planting programme which, from less than one million trees in 1967, is expanding to three million trees by the '71-'72 season.

Needless to say we eagerly await the era of container planting when 12 planters will plant one million trees per month and two such crews will be able to complete a three million tree planting programme in six weeks in the spring. The time and money saved will then be available for growth promoting silvicultural treatments in the plantations already established - Contributed by $\mathbf{M}$. Crown, Pacific Logging Company Ltd., Victoria, B.C.

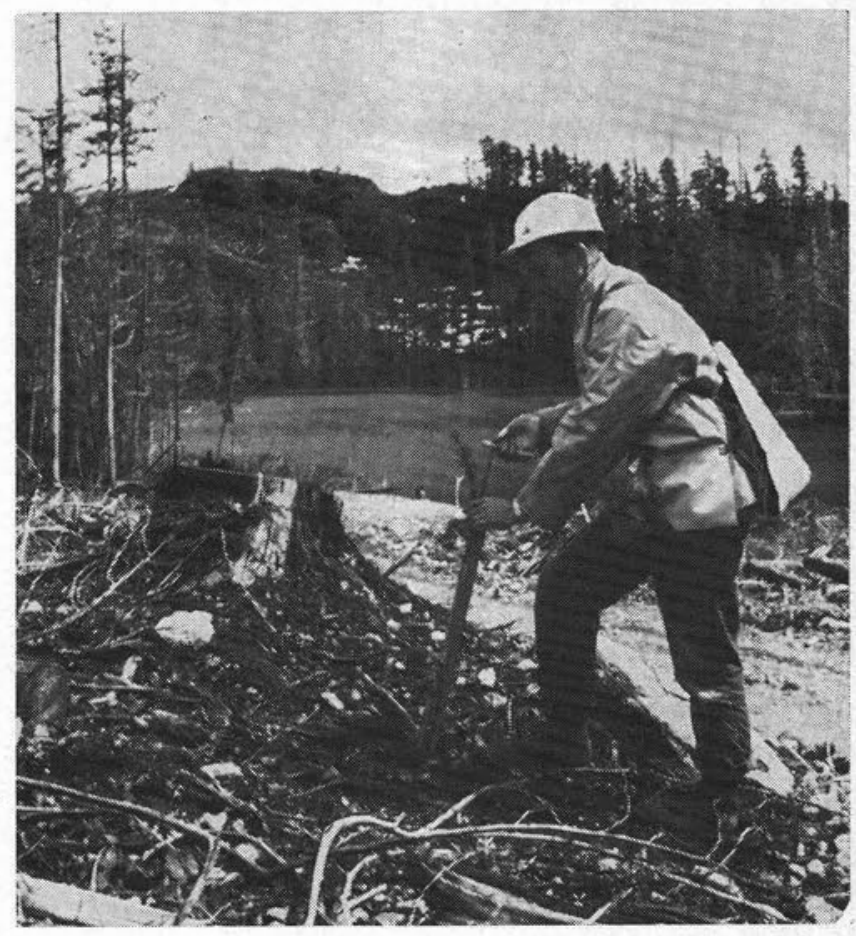

"Mud-packs" are regular 1-0 and 2-0 seedlings lifted from conventional nurseries. A peat-clay mixture is squeezed around the roots and the "mud" is partially dried until it is firm. These "mud packs" are then either put into cold storage, or planted in the field using the planting tool illustrated 


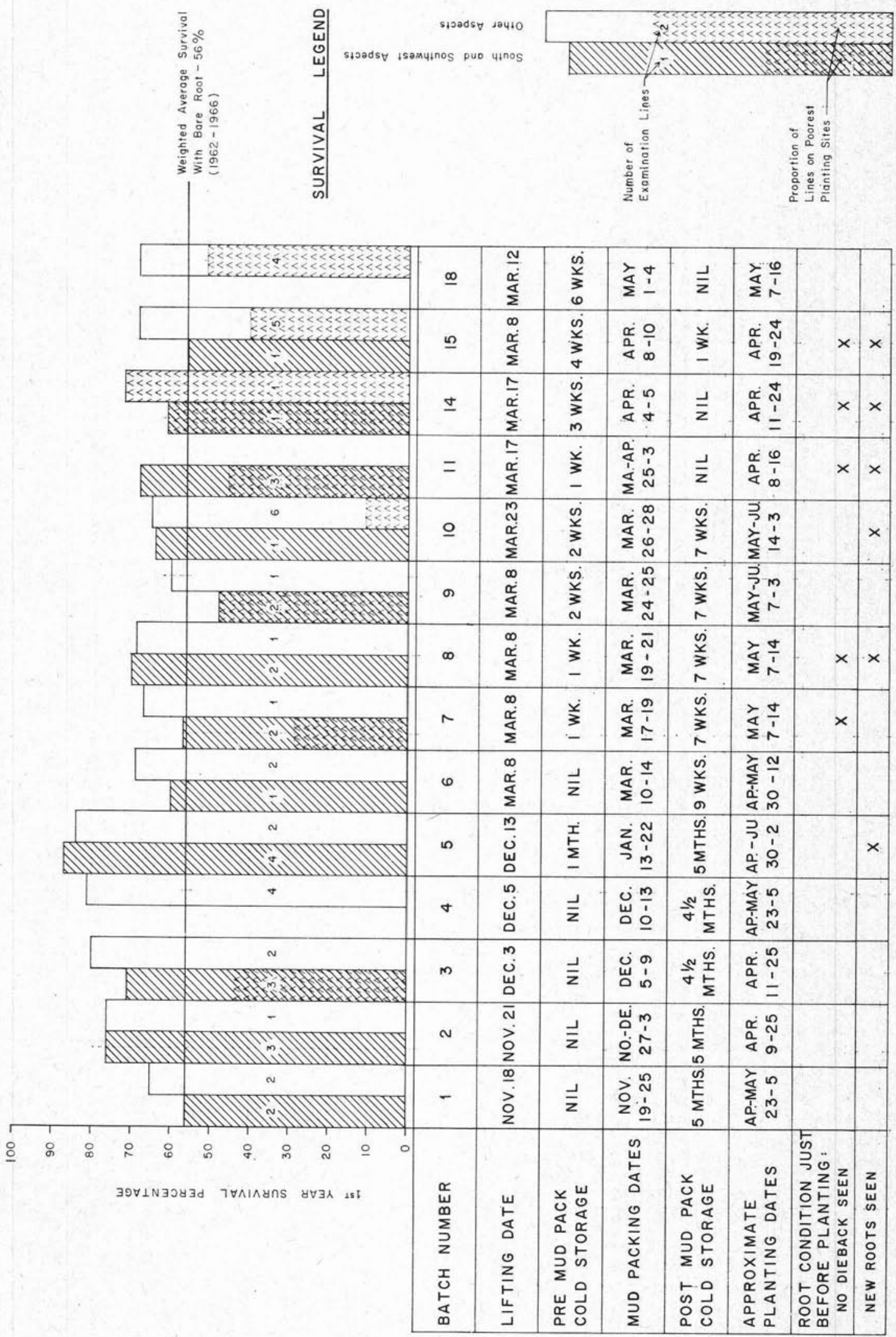

